\title{
Experimental study on the design of orifice pulse tube refrigerator
}

\author{
B.J. Huang *, G.J. Yu \\ Department of Mechanical Engineering, National Taiwan University, Taipei, Taiwan
}

Received 25 January 1999; received in revised form 4 May 2000; accepted 18 May 2000

\begin{abstract}
An experimental study on the design of a single-stage orifice pulse tube refrigerator (OPTR) was carried out. It was shown experimentally that there exists an optimum operating frequency which increases with decreasing pulse tube volume. For a fixed pulse tube volume, increasing the pulse tube diameter will improve the performance. The experimental results are used to derive a correlation for the performance of OPTR which correlates the net cooling capacity with the operating conditions and the dimensions of the OPTR. (C) 2001 Elsevier Science Ltd and IIR. All rights reserved.
\end{abstract}

Keywords: Cryorefrigerator; Pulse tube; Performance; Parameter single stage system

\section{Etude expérimentale sur la conception d'un réfrigérateur à tube à pulsation à orifice}

\section{Résumé}

Les auteurs ont effectué une étude expérimentale sur un réfrigérateur monoétagé à tube à pulsation à orifice (RTPO). Ils on montré qu'il existe une fréquence de fonctionnement optimale qui augmente en fonction de la diminution du volume du tube à pulsation. Pour un volume de tube à pulsation donné, l'augmentation du diamètre du tube à pulsation améliora la performance. Les résultats expérimentaux sont utilisés afin de développer une corrélation de la performance du RTPO et cette dernière est également fonction de la puissance frigorifique nette selon les conditions de fonctionnement et les dimensions du RTPO. (C) 2001 Elsevier Science Ltd and IIR. All rights reserved.

Mots clés : Cryoréfrigérateur ; Tube à pulsation ; Performance ; Paramètre ; Système monoétagé

\section{Introduction}

The performance of orifice pulse tube refrigerator (OPTR) has been improved significantly in recent years.

\footnotetext{
* Corresponding author. Tel.: + 886-2-2363-4790; fax: + 8862-2364-0549.

E-mail address: bjhuang@tpts.6.seed.net.tw (B.J. Huang).
}

Some design criteria are concluded from many studies. It has been realized that, for a better performance of OPTR, the designer had better follow some design guidelines, as summarized by Radebaugh [1]: (1) reducing the dead volumes of the OPTR as much as possible in connecting tubes, cold-end and hot-end spaces, and compression chamber, in order to reduce the thermodynamic loss; (2) using a high efficiency regenerator in order to reduce the heat transfer loss; (3) designing an 


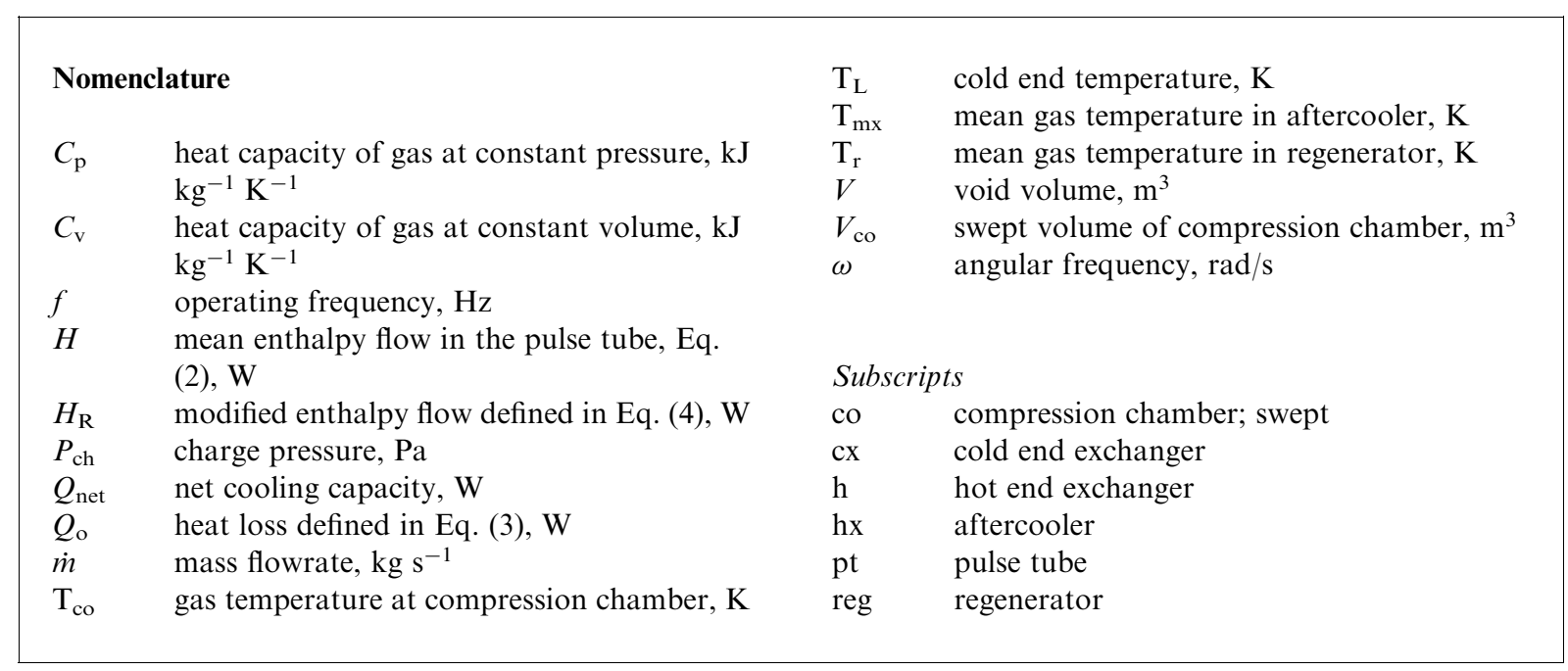

adequate flow straightening device at both ends of the pulse tube in order to reduce the turbulence loss in pulse tube; (4) good machining of the pulse tube and using a thin pulse-tube wall in order to reduce the fluid frictional loss and the heat conduction loss; (5) selecting an adequate orifice device and reservoir volume in order to provide an optimum phase shift between flowrate and pressure wave; (6) carefully selecting the dimensions of the pulse tube in order to match with the compressor and the regenerator for a given charge pressure and cold-end temperature. Many experiences reveal that the first 5 guidelines are easy to follow. The last one, concerning the pulse tube design, is the most difficult part in the design of an OPTR. Many researchers attempted to develop a design tool by using an analytical or numerical method [1-11]. The design of an OPTR, however, still relies mainly on experiences so far.

It is desirable for a designer to hold at hand a simple relation which correlates the sizes of pulse tube, regenerator, reservoir, compressor swept volume and orifice with the performance of an OPTR, e.g. net cooling capacity, at a given operating frequency, pressure and cold-end temperature.

To derive a correlation for the design of an OPTR, we carried out an experimental study. We focused on the design of a single-stage OPTR. The testing results were used to derive an empirical relation for the design of an OPTR.

\section{Experimental design}

In order to investigate the effect of pulse tube dimension on the OPTR performance, we built 7 OPTRs with different pulse tube diameters and lengths. The schematic diagram of the OPTR is shown Fig. 1. Table 1 summarizes the design specifications.

A valveless DC motor-driven compressor with ceramic cylinder and dry-lubrication piston was built in the present study. The swept volume of the compressor is 16

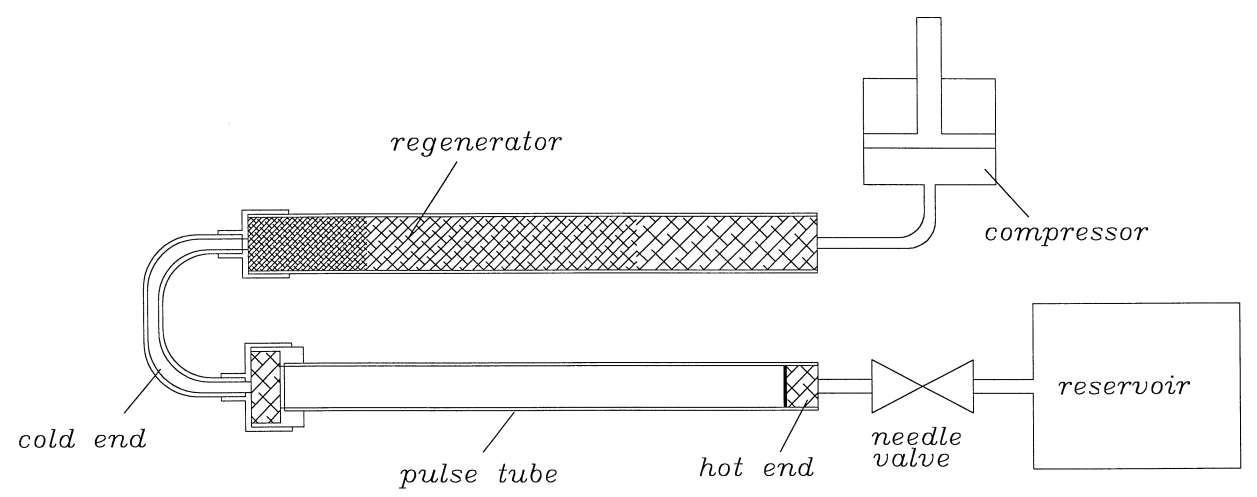

Fig. 1. Schematic diagram of single-stage orifice pulse-tube refrigerator.

Fig. 1. Schéma d'un réfrigérateur monoétage à pulsation à orifice. 
Table 1

Specifications of orifice pulse-tube refrigerators

Tableau 1

Spécifications des réfrigérateurs à pulsation à orifice

\begin{tabular}{lllll}
\hline OPTR model & \multicolumn{2}{l}{ Pulse tube } & $\mathrm{V}_{\mathrm{pt}} / \mathrm{V}_{\mathrm{co}}$ \\
\cline { 2 - 4 } & $\begin{array}{l}\text { Diameter } \\
\mathrm{mm}\end{array}$ & $\begin{array}{l}\text { Length } \\
\mathrm{mm}\end{array}$ & $\begin{array}{l}\text { Volume } \\
\mathrm{cm}^{3}\end{array}$ & \\
\hline OPT1 & 8.9 & 90 & 5.6 & 0.35 \\
OPT2 & 8.2 & 106 & 5.6 & 0.35 \\
OPT3 & 7.4 & 130 & 5.6 & 0.35 \\
OPT4 & 7.4 & 110 & 4.7 & 0.30 \\
OPT5 & 7.4 & 90 & 3.9 & 0.24 \\
OPT6 & 8.0 & 90 & 4.5 & 0.28 \\
OPT7 & 6.0 & 90 & 2.5 & 0.16 \\
\hline
\end{tabular}

Compressor swept volume: $16 \mathrm{~cm}^{3}$

Reservoir volume: $80 \mathrm{~cm}^{3}$

Regenerator:

diameter $9 \mathrm{~mm}$

screen mesh/layers: 400/180 200/700 150/400

$\mathrm{cm}^{3}$ and the reservoir volume is fixed at $80 \mathrm{~cm}^{3}$ for all the 7 OPTRs. Air cooling at the hot end was used. The regenerator is made from a stainless steel wire screen, 9 $\mathrm{mm}$ in diameter; 180 layers of 400 mesh, 700 layers of 200 mesh, and 400 layers of 150 mesh screen discs.

OPT1-OPT3 are designed with identical pulse tube volume but with a different diameter for studying the effect of pulse tube diameter. OPT3-OPT5 have the identical pulse tube diameter but with different length and volume; OPT5-OPT7 have an identical pulse tube length but with different diameter and volume.

Helium gas at $99.999 \%$ purity was used as the working fluid. The cold head was put in a vacuum chamber with a pressure kept at $10^{-5}$ Torr $\left(1\right.$ Torr $=133.29 \mathrm{~N} \mathrm{~m}^{-2}=1$ $\mathrm{mmHg}$ ). An electrical heater was placed on the cold end for heating to emulate the cooling load. A needle valve was used as the orifice. The flow resistance of the needle valve was measured separately using uni-direction helium gas flow. The following empirical relation for the flow resistance of the needle valve is obtained:

$R_{\mathrm{F}} \equiv \frac{\mathrm{d} \Delta P}{\mathrm{~d} \dot{m}}=1.14 \times 10^{13} \dot{m}+1.279 \times 10^{10}$

where $\dot{m}$ is the mass flowrate in $\mathrm{kg} / \mathrm{s} ; R_{\mathrm{F}}$ is the flow resistance in $\mathrm{m}^{-1} \mathrm{~s}^{-1} ; \Delta P$ is the pressure drop across the needle valve, in Pa. During the tests, the needle valve opening is fixed at the opening having the above flow resistance. This valve opening was experimentally found to be the optimum opening for the 7 OPTR for obtaining the lowest cold-end temperature at zero cooling capacity. Fixing the valve opening allows us to study the effect of pulse tube design on the OPTR performance.

\section{Performance tests of OPTR}

The performance of a OPTR can be evaluated from the cold end temperature at zero cooling capacity, i.e. the "minimum temperature". All the 7 OPTR are tested separately except in testing the performance of each OPTR at various operating frequencies, in which the experimental run is allowed to continue with changes to frequency without restarting the equipment. This may cause the problem of performance repeatability. However, some separate test runs at different frequencies for a given OPTR have shown that the test results can be repeated, with the minimum cold-end temperature variation within $\pm 3 \mathrm{~K}$.

\subsection{Effect of pulse tube diameter (pulse tube volume fixed)}

Fig. 2 are the test results for the OPTR with identical pulse tube volume but with different diameters and lengths. It shows that the performance of OPT1 is the best as compared to OPT2 and OPT3. It is shown experimentally that there exists an optimum operating frequency. The optimum frequencies are approximately identical around $10 \mathrm{~Hz}$ for the three OPTRs (OPT1OPT3). It is concluded that for fixed volume of the pulse tube, the performance of a OPTR tends to increase with increasing pulse tube diameter as shown in Fig. 2. This coincides with some findings that the flow pattern inside the pulse tube affects the performance of an OPTR. Smaller pulse tube diameter causes the flow to easily become turbulent and reduce the heat pumping effect due to gas dispersion and back mixing.

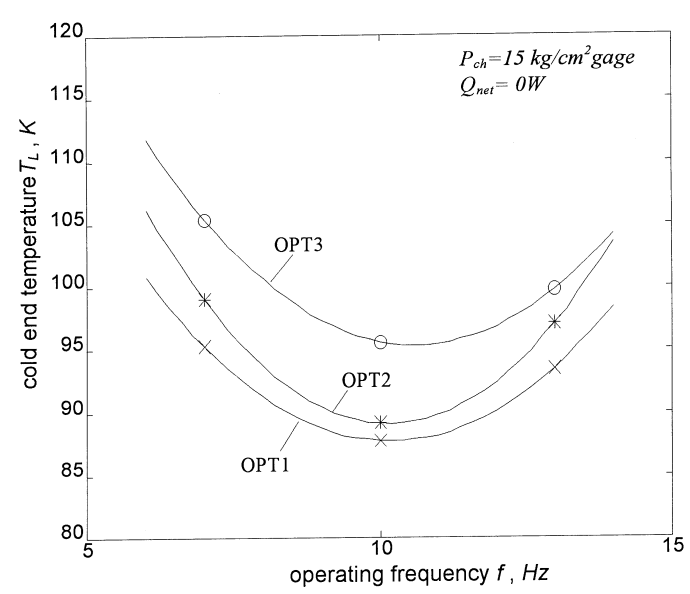

Fig. 2. Variation of minimum cold end temperature with operating frequency for fixed pulse tube volume.

Fig. 2. Variation de la température minimale côté froid en fonction de la fréquence de fonctionnement pour un volume de tube à pulsation donné. 


\subsection{Effect of pulse tube volume and length (diameter fixed)}

For OPT3-OPT5, the inside diameters of the pulse tubes are fixed, but the length and the volume of the pulse tube are changed. Fig. 3 shows that the performance of OPTR tends to increase with decreasing length and volume of the pulse tube. However, the optimum operating frequency increases with decreasing pulse tube volume too.

\subsection{Effect of pulse tube volume and diameter (length fixed)}

For fixed pulse tube length, the optimum operating frequency tends to decrease with increasing diameter and volume as shown in Fig. 4. For OPT7, the pulse tube diameter is the smallest $(6 \mathrm{~mm})$ and reveals a higher optimum operating frequency and a lower performance.

\subsection{Optimum operating frequency}

Figs. 2-4 show that there exists an optimum operating frequency for OPTR. It is interesting to see that the optimum operating frequency decreases monotonically with increasing pulse tube volume as shown in Fig. 5. A smaller volume results in a higher optimum frequency irrespective of the diameter and the length. The optimum frequency reflects the dynamic behavior of the OPTR. It is difficult to explain this phenomenon. The pulse tube seems just to act as a well-mixed chamber similar to a reservoir at the optimum frequency operation.

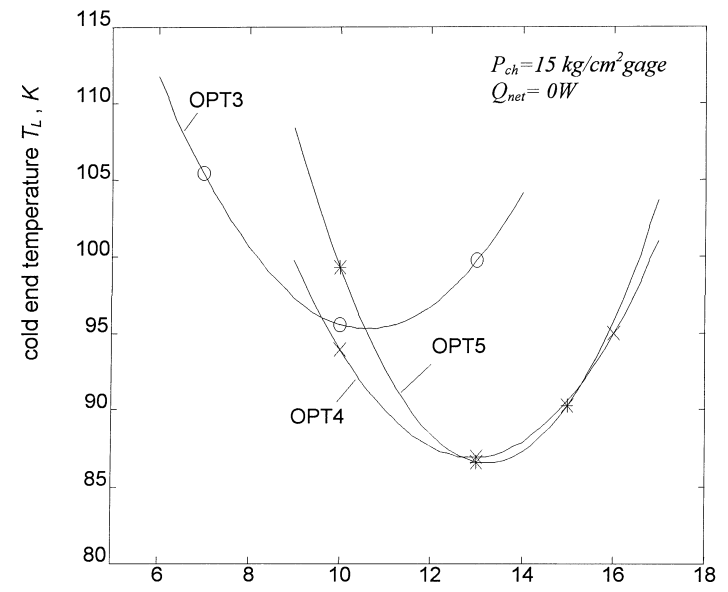

Fig. 3. Variation of minimum cold end temperature with operating frequency for fixed pulse tube diameter.

Fig. 3. Variation de la température minimale côté froid en fonction de la fréquence de fonctionnement pour un diamètre de tube à pulsation donné.

\subsection{Lowest minimum temperature achieved}

The lowest minimum temperature obtained in the present study using the $16 \mathrm{~cm}^{3}$ compressor and air cooling at the hot end is $85 \mathrm{~K}$ for OPT5 at $13 \mathrm{~Hz}$. This result is quite reasonable compared to the results of other investigators. Using water cooling at the hot end of an OPTR, Liang et al. [13] used a $240 \mathrm{~cm}^{3}$ compressor to achieve a minimum temperature of $49 \mathrm{~K}$; while Radebaugh [1] used a $25 \mathrm{~cm}^{3}$ compressor to achieve a minimum temperature of $67 \mathrm{~K}$.

\section{6. $C O P$}

The COP of the 7 OPTRs at $T_{\mathrm{L}}=120 \mathrm{~K}$ are measured and presented in Fig. 6. The highest COP is around

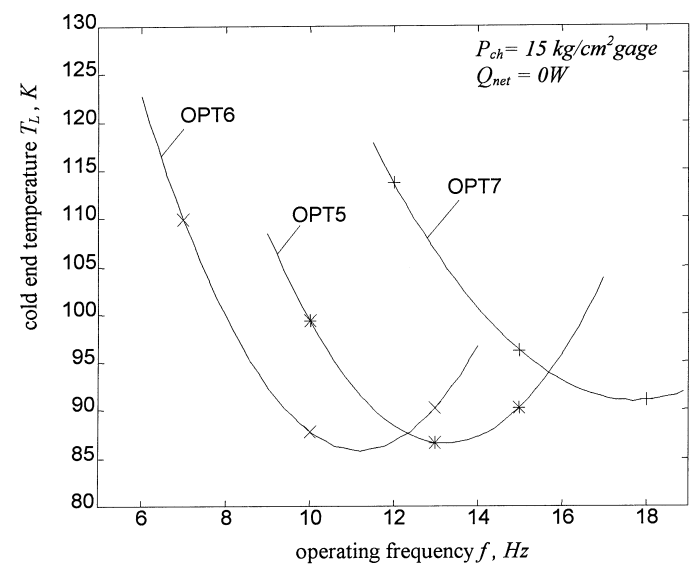

Fig. 4. Variation of minimum cold end temperature with operating frequency for fixed pulse tube length.

Fig. 4. Variation de la température minimale côté froid en fonction de la fréquence de fonctionnement pour une longueur de tube à pulsation donnée.

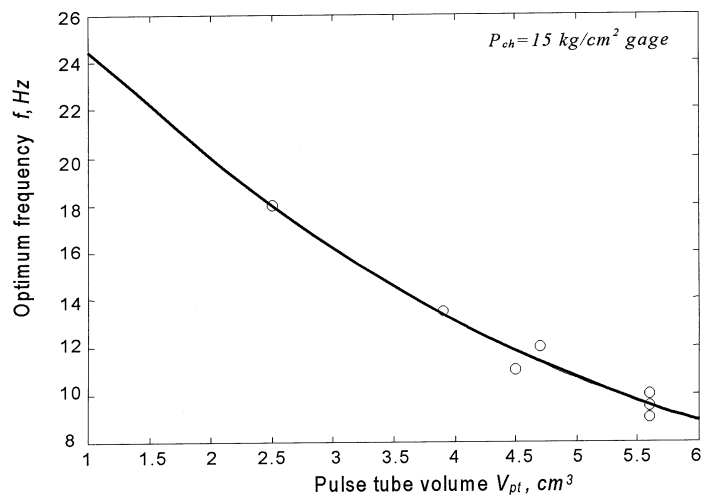

Fig. 5. Variation of optimum operating frequency with pulse tube volume.

Fig. 5. Variation de la fréquence de fonctionnement optimale en fonction du volume du tube à pulsation. 
0.025 for OPT1 at $10 \mathrm{~Hz}$. The cooling capacity of OPT1 at $120 \mathrm{~K}$ and $10 \mathrm{~Hz}$ is $2.6 \mathrm{~W}$, as shown in Fig. 7, with power consumption $104 \mathrm{~W}$. This is much better than that of a commercial OPTR with rotary valve design [14] (COP around 0.007).

The valveless compressor developed in the present study uses a ceramic-laminated cylinder with a drylubrication piston. The swept volume of the piston is 16 $\mathrm{cm}^{3}$ which is much smaller than those used by some other researches [1,12]. A DC motor with a rated power $200 \mathrm{~W}$ was used to drive the piston in the present study. This laboratory-made, light-weight compressor has been

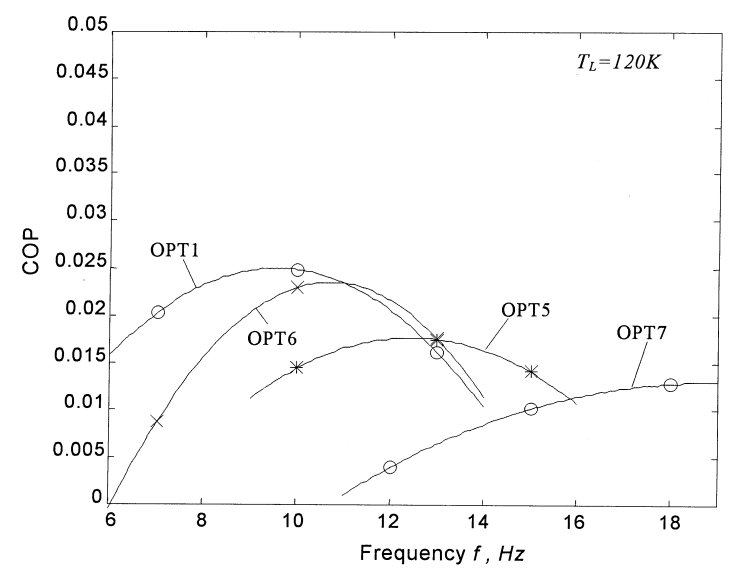

Fig. 6. Measured COP at $T_{\mathrm{L}}=120 \mathrm{~K}$.

Fig. 6. COP mesuré à $T_{L}=120 \mathrm{~K}$.

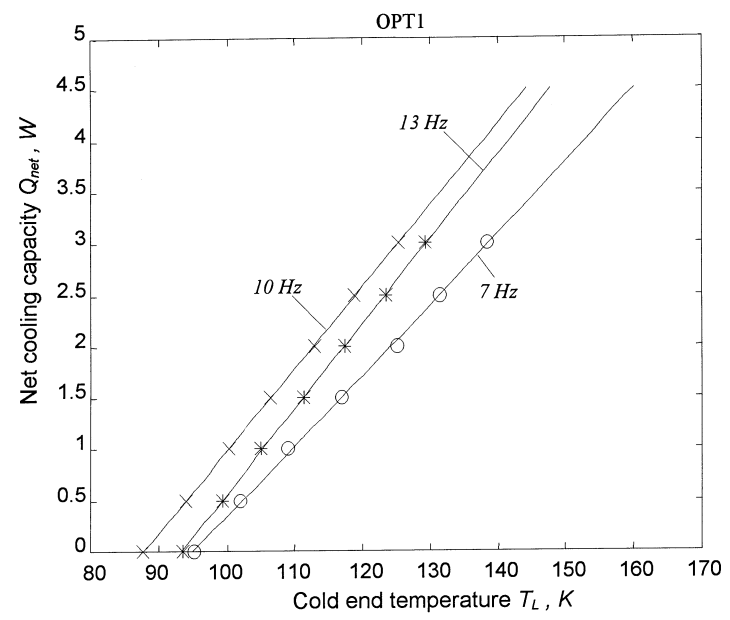

Fig. 7. Variation of net cooling capacity with cold end temperature at various frequencies for OPT1.

Fig. 7. Variation de la puissance frigorifique nette en fonction de la température côté froid pour diverse fréquences du TPO1. developed for many years and has passed a life test of $1000 \mathrm{~h}$.

A higher COP for the present OPTR can be obtained if the DC motor in the compressor is replaced by a highperformance one or water cooling at the hot end of the OPTR is adopted.

\section{Correlation for the performance of an OPTR}

Using the phaser concept and a thermodynamic model, Radebaugh [1] derived an algebraic equation for the gross power or the mean enthalpy flow in the pulse tube:

$H=\frac{\omega T_{\mathrm{L}} P_{\mathrm{ch}}\left(V_{\mathrm{co}} / T_{\mathrm{co}}\right)^{2}}{16\left[\frac{V_{\mathrm{co}}}{2 k T_{\mathrm{co}}}+\frac{V_{\mathrm{hx}}}{T_{\mathrm{mx}}}+\frac{V_{\mathrm{reg}}}{T_{\mathrm{r}}}+\frac{V_{\mathrm{cx}}}{T_{\mathrm{L}}}+\frac{V_{\mathrm{pt}}}{\gamma T_{\mathrm{L}}}+\frac{V_{\mathrm{h}}}{T_{\mathrm{L}}}\right]}$

where $\omega$ is the angular frequency in $\mathrm{rad} / \mathrm{s} ; T_{L}$ is the cold end temperature in $\mathrm{K} ; P_{\mathrm{ch}}$ is the charge pressure in $\mathrm{N} /$ $\mathrm{m}^{2}$; Vco is the swept volume of the compressor in $\mathrm{m}^{3}$; $T_{\text {co }}$ is the average gas temperature in the compression chamber in $\mathrm{K} ; k$ is the exponent of the polytropic process which varies from 1 for isothermal compression to $\gamma\left(=C_{\mathrm{p}} / C_{\mathrm{v}}\right)$ for isentropic compression.

We attempted to derive a simple relation that can correlate the experimental data of the OPTR. We have observed the following facts which will help us to derive a correlation:

1. If we followed the aforementioned first 5 design guidelines, the effect of dead volumes of aftercooler, cold-end exchanger and hot-end exchanger becomes small. Therefore, the three $V / T$ terms in the denominator of Eq. (2) can be neglected.

2. The experimental results (Figs. 7-13) show that the net cooling capacity only slightly varies with operating frequency for frequencies $>10 \mathrm{~Hz}$.

Therefore, we derive the following relation to correlate the net cooling capacity of the OPTR with the mean enthalpy flow:

$Q_{\text {net }}=C H_{\mathrm{R}}-Q_{\mathrm{o}}$

where $H_{\mathrm{R}}$ is a mean enthalpy flow in the pulse tube whose mathematical expression is different from Eq. (2), called "modified mean enthalpy flow"; $C$ and $Q_{\text {o }}$ are the empirical coefficients; $Q_{\mathrm{o}}$ represents the loss. We obtain the following empirical relation for $H_{\mathrm{R}}$ from data processing using the present test results for the 7 OPTRs:

$H_{\mathrm{R}}=\frac{T_{\mathrm{L}} P_{\mathrm{ch}}\left(V_{\mathrm{co}} / T_{\mathrm{co}}\right)^{2}}{16 \omega^{0.1}\left[\frac{V_{\mathrm{co}}}{2 k T_{\mathrm{co}}}+\frac{V_{\mathrm{pt}}}{\gamma T_{\mathrm{L}}}+\frac{V_{\mathrm{reg}}}{T_{\mathrm{r}}}\right]}$, Watt 
where $k=1$. It should be noted that the unit of $H_{\mathrm{R}}$ is Watt for the designated dimensions of the variables: $\omega(=2 \pi f)$ in $\mathrm{rad} / \mathrm{s}$, all temperatures $T$ 's in $\mathrm{K}, P_{\mathrm{ch}}$ in $\mathrm{MPa}$, V's in $\mathrm{m}^{-3}$. Eq. (4) is similar to Radebaugh's relation of the mean enthalpy flow $H$, Eq. (2), with change in the term $\omega(=2 \pi f)$ from numerator to denominator and having an exponent. In order to coincide with the test results, all the units of each variable in Eq. (4) must strictly follow the above definitions.

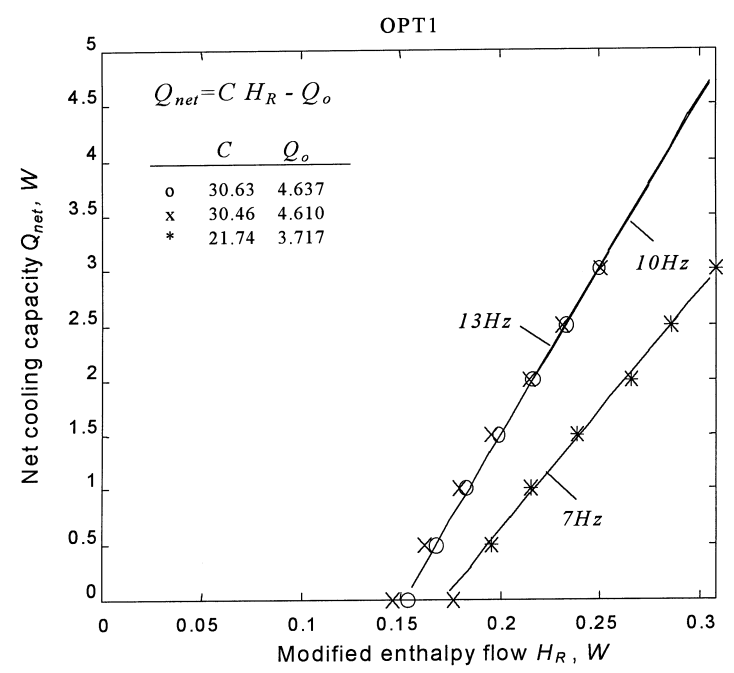

Fig. 8. Variation of net cooling capacity with modified enthalpy flow for OPT1.

Fig. 8. Variation de la puissance frigorifique nette en fonction $d u$ flux enthalpique modifié pour le TPO1.

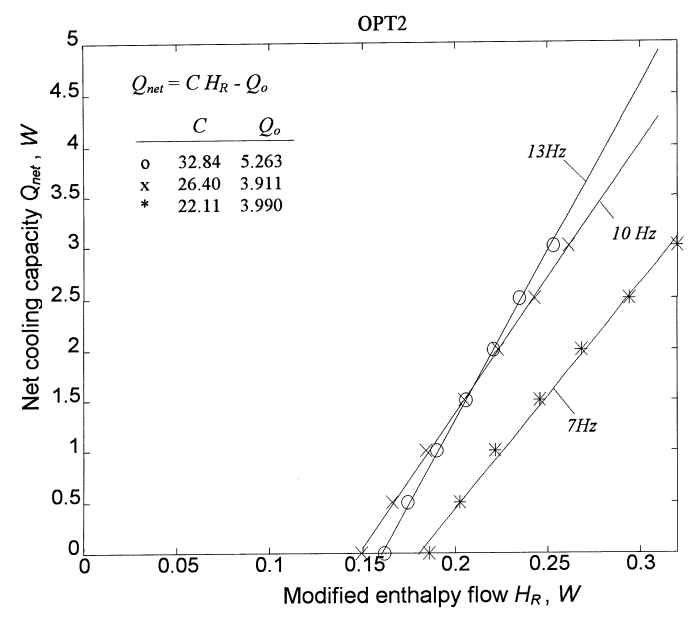

Fig. 9. Variation of net cooling capacity with modified enthalpy flow for OPT2.

Fig. 9. Variation de la puissance frigorifique nette en fonction du flux enthalpique modifié pour le TPO2.
We found that all the experimental $Q_{\text {net }} v s H_{\mathrm{R}}$ curves coincide at higher operating frequencies $(>10 \mathrm{~Hz})$ according to Eq. (3), as shown in Figs. 8-13, except for OPT7 (Fig. 14). The performance of OPT7 deviates relatively large from Eq. (3). This is due to the small inside diameter of the pulse tube which changes the gaseous flow pattern inside the pulse tube and reduce the heat pumping effect.

The term $\mathrm{CH}_{\mathrm{R}}$ in Eq. (3) represents the gross power or mean enthalpy flow in the pulse tube, while $Q_{\text {o }}$

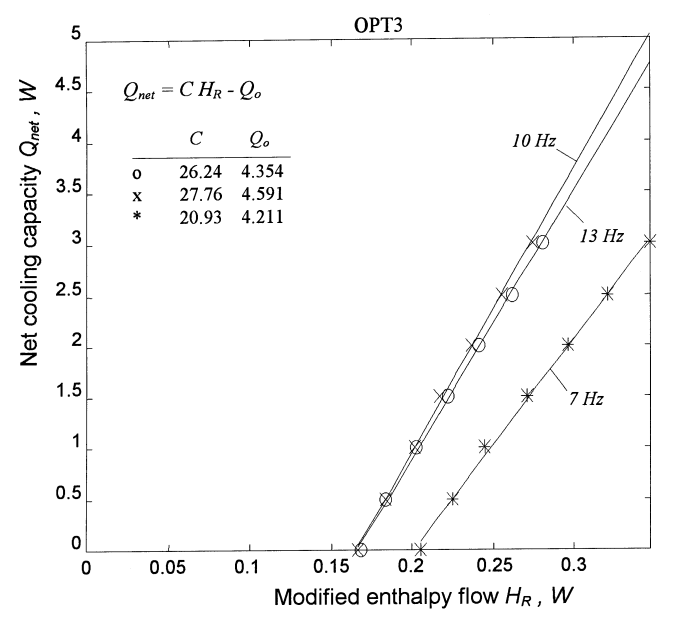

Fig. 10. Variation of net cooling capacity with modified enthalpy flow for OPT3.

Fig. 10. Variation de la puissance frigorifique nette en fonction du flux enthalpique modifié pour le TPO3.

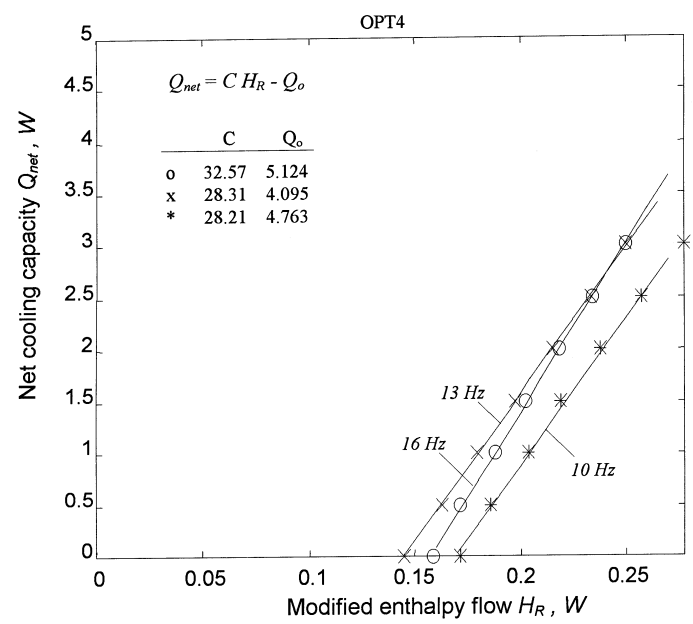

Fig. 11. Variation of net cooling capacity with modified enthalpy flow for OPT4.

Fig. 11. Variation de la puissance frigorifique nette en fonction du flux enthalpique modifié pour le TPO4. 
represents the overall loss of a OPTR. It is seen from Table 2 that, the value of $C$ falls in a narrow range, from 25 to 32, and the value of $Q_{\mathrm{o}}$ falls within the range from 3.8 to 5.2, independent of the design of OPTR. We can then conclude that Eq. (3) holds for optimum performance of a OPTR which occurs at higher operating frequencies $(>10 \mathrm{~Hz})$, as is shown in Fig. 15. The empirical correlation is

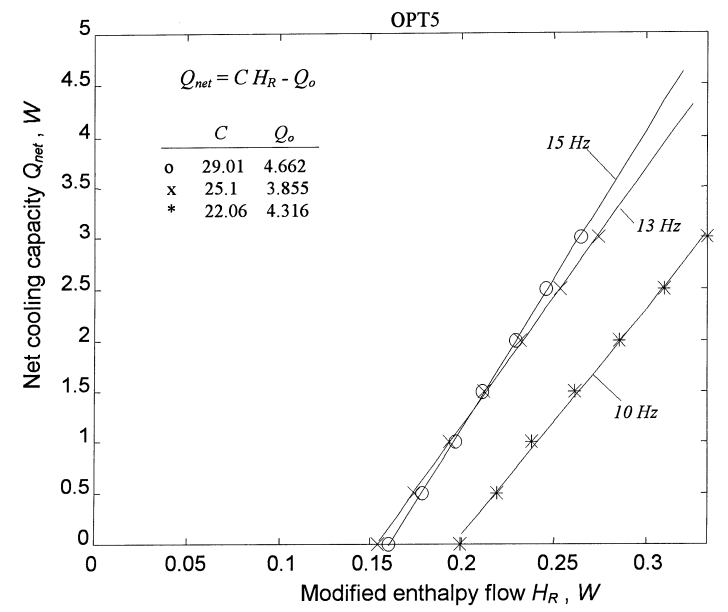

Fig. 12. Variation of net cooling capacity with modified enthalpy flow for OPT5.

Fig. 12. Figure 12. Variation de la puissance frigorifique nette en fonction du flux enthalpique modifié pour le TPO5.

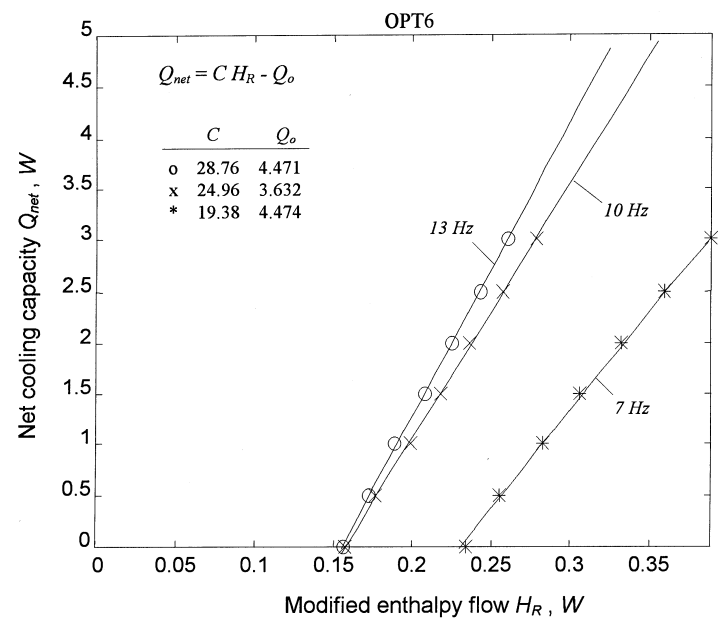

Fig. 13. Variation of net cooling capacity with modified enthalpy flow for OPT6.

Fig. 13. Variation de la puissance frigorifique nette en fonction du flux enthalpique modifié pour le TPO6.
$Q_{\text {net }}=27.39 H_{\mathrm{R}}-4.20$

The above correlation is valid for the present OPTR. But, it may probably be extended to the design of an OPTR for the following conditions: (1) the first 5 design guidelines is followed, (2) the operating frequency $f(=\omega / 2 \pi)>10 \mathrm{~Hz}$; (3) the orifice resistance $R_{\mathrm{F}}$ is adjusted and fixed in order for obtaining the lowest cold-end temperature at zero-cooling-load condition, here, fixed according to Eq. (1); (4) the reservoir volume is fixed at $80 \mathrm{~cm}^{3}$, but a larger volume may be allowed since it changes the OPTR performance very little.

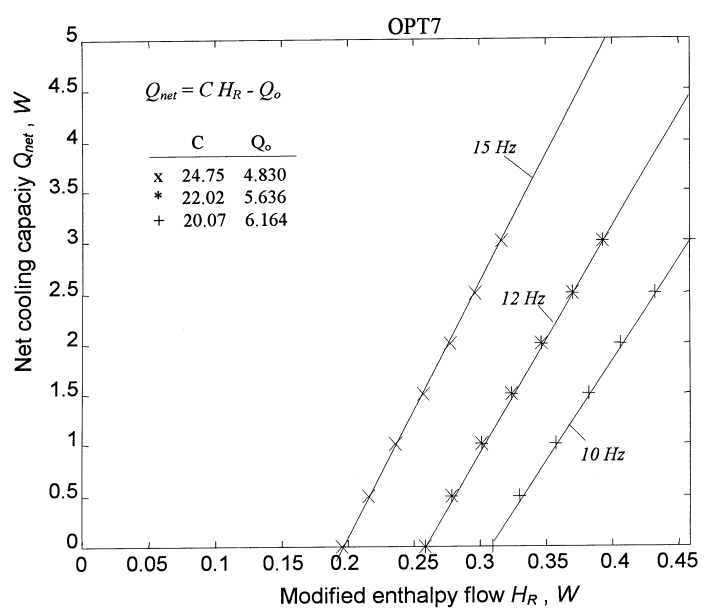

Fig. 14. Variation of net cooling capacity with modified enthalpy flow for OPT7.

Fig. 14. Variation de la puissance frigorifique nette en fonction du flux enthalpique modifié pour le TPO7.

Table 2

The empirical coefficients determined from test results

Tableau 2

Coefficients empiriques déterminés à partir des résultats d'essais

\begin{tabular}{llll}
\hline OPTR model & $\mathrm{f}(>10 \mathrm{~Hz})$ & $\mathrm{C}$ & $\mathrm{Q}_{0} \mathrm{~W}$ \\
\hline OPT1 & 13 & 30.63 & 4.637 \\
OPT2 & 13 & 32.84 & 5.263 \\
OPT3 & 13 & 26.24 & 4.354 \\
OPT4 & 16 & 32.57 & 5.124 \\
& 13 & 28.31 & 4.095 \\
OPT5 & 15 & 29.01 & 4.662 \\
& 13 & 25.10 & 3.855 \\
OPT6 & 13 & 28.76 & 4.471 \\
\hline
\end{tabular}




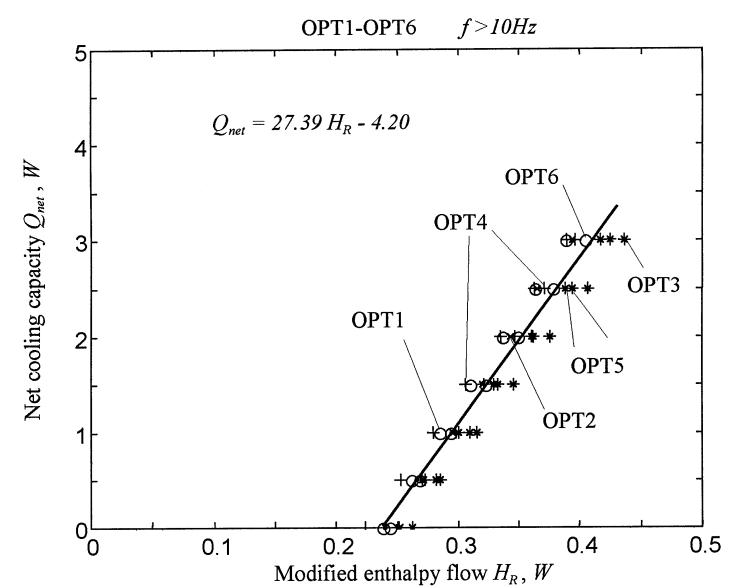

Fig. 15. Empirical correlation of net cooling capacity with modified enthalpy flow for OPTR.

Fig. 15. Coefficient empirique pour la puissance frigorifique nette en fonction du flux enthalpique modifié pour le RTPO.

\section{Discussions and conclusion}

The present study shows that the dimension selection of the pulse tube plays an important role in the OPTR performance. For a fixed pulse-tube volume, increasing the pulse-tube diameter will improve the performance. It was shown experimentally that, there exists an optimum operating frequency which increases with decreasing pulse-tube volume. The lowest temperature obtained in the present study using a $16 \mathrm{~cm}^{3}$ compressor and air cooling at the hot end is $85 \mathrm{~K}$ for OPT5 at $13 \mathrm{~Hz}$. The best performance of an OPTR (OPT1) has a cooling capacity $2.6 \mathrm{~W}$ at $120 \mathrm{~K}$ and $10 \mathrm{~Hz}$ with power consumption $104 \mathrm{~W}$ and $\mathrm{COP}=0.025$.

The experimental results are used to derive a correlation for the performance of an OPTR, Eq. (5). However, it is noticeable that this correlation was derived from 6 OPTR which have the ratio $V_{\mathrm{pt}} / V_{\text {co }}$ in the range from 0.24 to 0.35 . However, for $T_{\mathrm{L}}=120 \mathrm{~K}$ and $T_{\text {co }}=350 \mathrm{~K}$, the optimum ratio $V_{\mathrm{pt}} / V_{\text {co }}=0.72$ according to Radebaugh's theory [1]. This indicates that the simple enthalpy flow relation, Eq. (2), derived by Radebaugh can not fit the test results of the present OPTR. Eq. (5) is thus derived as a correction. Though Eq. (5) is derived from the test results of the present 7 OPTRs, it may be applicable for the other design, as long as the aforementioned 5 design guidelines of an OPTR are followed and the orifice resistance or the needle valve opening is adjusted for obtaining the lowest cold-end temperature at zero cooling capacity. But some error may still exist due to the on-hand technology such as the design of the compressor and lubricating medium, fabricating technology and material used in the regenerator and pulse tube etc. Eq. (5) can be further corrected for the hardware design which is largely different from the present design.

It is also noticeable from Fig. 7 that $Q_{\text {net }}$ varies linearly with $T_{\mathrm{L}}$. Meanwhile, $Q_{\text {net }}$ varies linearly with $H_{\mathrm{R}}$ too as shown in Fig. 8. This implies that $H_{\mathrm{R}}$ could vary linearly with $T_{\mathrm{L}}$. This also means that Eq. (4) can be approximated by a linear relation of $T_{\mathrm{L}}$, e.g., $H_{\mathrm{R}}=$ $a T_{\mathrm{L}}+b$, where the coefficients $a$ and $b$ will vary only implicitly with the design of the OPTR and operating frequency and pressure. However, keeping Eq. (4) will retain the form of Radebaugh's relation, Eq. (2), for easy understanding and implementation. This also allows us to clearly see how the enthalpy flow and the sizes of pulse tube, compressor and regenerator affect the cold-end temperature, operating pressure and frequency, etc.

Finally, it should be pointed out that Eq. (5) correlates the net cooling capacity with the operating conditions (pressure and temperatures) and the dimensions of the OPTR. Hence, it provides a useful means for the design of an OPTR. But, the effect of flow resistance of the needle valve or orifice is still not included explicitly in Eq. (5). It only requires that an optimum valve opening can be adjusted on field. Further studies are still required to investigate the effect of valve opening and derive a more thorough correlation for an OPTR performance.

\section{Acknowledgement}

The present study was supported by National Science Council, Taiwan, through Grant No.CS83-0210-D002011.

\section{References}

[1] Radebaugh R. A review of pulse tube refrigerator. Adv Cryogenic Eng 1990;35:1191-205.

[2] Huang BJ, Chuang MD. System design of orifice pulsetube refrigerator using linear flow network analysis. Cryogenics 1996;36(11):889-902.

[3] Kittel P, Kashani A, Lee JM, Roach PR. General pulse tube theory. Cryogenics 1996;36(10):849-57.

[4] Wang C, Wu PY, Chen ZQ. Numerical analysis of doubleinlet pulse tube refrigerator. Cryogenic 1994;33(5):526-30.

[5] Cai JH, Wang JJ, Zhu WX, Zhou Y. Experimental analysis of the multi-bypass principle in pulse tube refrigerator. Cryogenics 1994;34(9):713-5.

[6] Zhu SW, Chen ZQ. Isothermal model of pulse tube refrigerator. Cryogenics 1994;34(7):591-5.

[7] Mirels, H. Linearized pulse tube cryocooler theory. In: Proceedings of the 7th International Cryocoolers Conference Vol.1, Santa Fe, New Mexico, USA, 17-19 November 1992, published by Phillips Lab., Report No.PL-CP-93-1001 1993: 221-232. 
[8] David M, Maechal JC, Simon Y, Guilpin C. Theory of ideal orifice pulse tube refrigerator. Cryogenics 1993;33(2):154-61.

[9] Harpole, GM, Chan CK. Pulse tube cooler modeling. In: Proceedings 6th International Cryocooler Conference Vol.1, Plymouth, Massachusetts, USA, 25-26 October, 1990, published by David Tayllor Research Center, Bethesda, MD 20084-5000, U.S.A., 1991: 91-101.

[10] Baks M, Hirschberg A, van der Ceelen B, Guijsman HM. Experimental verification of an analytical model for orifice pulse tube refrigeration. Cryogenics 1990;30:947-51.
[11] Storch PJ, Radebaugh R. Development and experimental test of an analytical model of the orifice pulse tube refrigerator. Adv Cryogenic Eng 1988;33:851-9.

[12] Cai JH, Zhou Y, Wang JJ, Zhu WX. Experimental analysis of douclt-inlet principle in pulse tube refrigerators. Cryogenics 1993;33:522.

[13] Liang J, Zhou Y, Zhu W. Development of a single-stage pulse tube refrigerator capable of reaching 49K. Cryogenics 1990;30:49.

[14] Catalog of PTRE CryoMini Pulse Tube Cryocooler, Iwatani Co., Japan, 1995. 